\title{
THE EFFECTS OF COMPANY RECRUITMENT PRACTICES ON JOB SEEKERS' PERCEIVED EMPLOYMENT BRAND EQUITY AND INTENTIONS TO PURSUE JOB OPPORTUNITIES
}

\author{
JIAN HAN \\ CHRISTOPHER J. COLLINS \\ Department of Human Resource Studies \\ School of Industrial and Labor Relations \\ Cornell University \\ Ithaca, NY 14853-3901
}

\begin{abstract}
The early phase of recruitment is essential to staffing success: larger applicant pools permit managers to be more selective when making job offers and increase the overall utility of selection systems (Murphy, 1986). Despite the importance of this early stage of recruitment, little is known about how early recruitment practices affect potential applicants' intentions and decisions to pursue job opportunities (Breaugh \& Starke, 2000). In addition, existing research on the first phase of recruitment is limited because most recruitment research has only concentrated on a small range of recruitment practices that are typically deployed during later phases of recruitment like the job interview (Rynes, 1991). The purpose of this paper is to use the brand-equity literature as a conceptual framework for exploring how a company's mix of recruitment activities affects job seekers' perceived employment brand equity and their intentions to pursue job opportunities.
\end{abstract}

\section{THEORETICAL BACKGROUND AND HYPOTHESES}

\section{Dimensions of Employment Brand Equity}

Brands have been identified as a critical means for making points of differentiation between products and creating competitive advantage for organizations (Aaker, 1991). Customer-based brand equity has been defined as consumers' beliefs about a product that affect their preferences and purchasing decisions relative to other unbranded or weakly branded products with similar attributes (Aaker, 1991, 1996; Keller, 1993). Similarly, we define employment brand equity as outcomes of applicants decision opportunities attributable to job seekers' beliefs about the company as an employer. While different sets of researchers have identified different beliefs that are important, we focus on three dimensions that are included in most descriptions of brand equity: brand awareness, brand associations, and perceived quality.

Brand awareness. From a memory perspective, brand awareness relates to the likelihood and ease with which a brand name under different conditions (Rossiter \& Percy, 1987). Greater awareness increases the likelihood that the brand will be included in the consideration set from which the final choice will be made (Aaker, 1991). Students searching for jobs on campus are often exposed to the recruitment efforts of several hundred companies and often have many choices when it comes to making application decisions. Thus, student application decisions may also be influenced by awareness that the company exists as a potential employer (Gatewood, et al, 1993; Turban and Greening, 1997). 
Brand associations. Once consumers recall a brand from memory or recognize the product on a store shelf, consumers use the associations about a brand held in their memory to make choices between brands (Gardner \& Levy, 1955; Aaker, 1991). Brand associations are made up of both their perceived attitudes about the brand and specific attributes associated with the brand that consumers hold in their memory (Keller, 1993). Perceived attitudes are consumers' overall evaluations of a brand and may be considered to be consumers' generalized feelings towards the brand (Wilke, 1986). Perceived attributes of a brand are the features on which products or services in a particular category are compared (Keller, 1993). Just as with consumers, job seekers are likely to choose a product when they have perceived associations about the brand that are strong, favorable, and unique.

Perceived quality. Perceived quality, a third key dimension of brand equity, has been defined as customers' perception of the overall quality or superiority of a product or service relative to relevant alternatives with respect to the intended purpose of the product (Kirmani and Zeithaml, 1993; Keller, 1998). Consumers are more willing to purchase a product if they believe that the product will fulfill their needs (Zeithaml, 1988). In effect, perceptions about quality are assessments about the fit of the product to the needs of the consumers making a purchase decision (Keller, 1998). Similarly, job seekers may be affected by their beliefs that the company will be a fit to their needs as an employee (e.g., Judge \& Cable, 1997).

\section{Effects of Recruitment Mix on Brand Equity}

If the dimensions of employment brand equity are the critical factors that drive job seekers application intensions and decisions, then it is important to understand how firms can influence job seekers perceptions of those attributes. Customer-based brand equity literature has suggested that firms can use a mix of marketing communication tools to effectively build stronger brand equity. Marketing communication activities contribute to brand equity by establishing the brand in memory and creating strong, favorable and unique brand association which are linked to the brand in the minds of consumers (Aaker \& Biel, 1993). The mix of marketing communication tools includes media advertising (TV, newspaper, radio, and other print media etc.), trade promotions, sponsorship and event marketing, and public relations (Aaker \& Biel, 1993). These options have different strengths, but they all act towards a common goal of building a strong and consistent brand equity.

In the early recruitment stage, employers also select various sources (e.g. advertising, referrals) to target and deliver messages to potential job applicants (Barber, 1998). The practical objectives and theoretical rationales of such recruitment activities in this stage are similar to those of the product marketing communications. Therefore, we rely on the customer-base marketing communication framework to discuss how to use a mix of recruitment practices to achieve stronger employment brand equity.

Advertising and Brand Equity. Advertising refers to paid, professionally designed messages, channeled through various media outlets, which are used to modify consumers' perceptions (Aaker, 1996). Because advertising is directly controlled by organizations, it can be crafted to create desirable brand-attribute associations in consumers' minds (Boulding, Lee, \& Staelin, 
1994) as well as to foster positive attitudes toward the brand (Milgrom \& Roberts, 1986; CobbWalgren et al., 1995). Recruitment advertising, in the form of brochures and job postings through various media (e.g. TV, magazine, radio etc.), has traditionally been used to disseminate information about openings (Rynes, 1991). Moreover, research suggests that such advertising has effects on employer brand equity that is similar to those observed in marketing.

Hypothesis 1: The extent of a company's practice in employment advertisement will be positively associated with job seekers' perceived employment brand equity.

Job Fairs and Employment Brand Equity. Trade shows are an important component of the marketing mix for many industrial products (e.g. Kerin \& Cron, 1987; Gopalakrishna \& Williams, 1992; Dekimpe, Francois, Gopalakrishna, Lilien, \& Van den Bulte, 1997). Because, trade shows blend elements of direct selling and advertising, they convey both personal and impersonal communication to satisfy potential buyers' needs for information in the buying process (Dekimpe et al. 1997). Job fairs, with the similar function of trade shows, continue to be an effective recruiting method among employers competing for college candidates (Roehling \& Cavanaugh, 2000). Since job fairs also provide both personal and impersonal communication, we assume that job fairs will promote job seekers' awareness of potential employers.

Hypothesis 2: The extent of a company's practice in job fairs will be positively associated with job seekers' perceived employment brand equity.

Sponsorship and Employment Brand Equity. As with advertising and trade promotion, corporate sponsorship activities have been used primarily to increase consumers' brand awareness (Aaker, 1996). Corporate sponsorships can improve both brand and corporate images by fostering positive affect among individuals who attend sponsored events or become aware of the sponsorship (Johar \& Pham, 1999). Following the trends in product marketing, many corporations have begun expanding their recruitment efforts to include sponsorships of campus activities to build awareness of employment opportunities (Poe, 2000). Therefore, we predicted that sponsorship will have a positive and significant impact on perceived brand equity.

Hypothesis 3: The extent of a company's sponsorship practices will be positively associated with job seekers' perceived employment brand equity.

Word-of-mouth Endorsements and Employment Brand Equity. World-of-mouth endorsements have a great impact on a consumer's beliefs about a product because it provides information and opinions that help to distinguish among brands (Keller, 1993). Because word-of-mouth are a source of information that does not seem to come directly from the company itself (CobbWalgren, Ruble, \& Donthu, 1995), and they are seen as more credible by consumers (CobbWalgren et al, 1995). Similarly, many recruiting companies build relationships with faculty and other key university contacts in hopes that these contacts will pass on information and positive opinions about their company to students who are beginning their job search (Poe, 2000). Thus, we expect that building relationships with key university contacts will lead to more positive perceptions of brand equity. 
Hypothesis 4: Building relationship with key university contacts will be positively associated with job seeker's perceived employment brand equity.

\section{Employment Brand Equity and Intentions to Pursue Job Opportunities}

Marketing researchers have consistently found that consumers decisions and purchase intentions are significantly and positively affected by brand equity (Keller, 1993; Aaker, 1996). Cable and Turban (2001) have argued that job seekers' intentions to pursue a job opportunity at an organization may be similarly influenced if the firm creates a strong employment brand. Indeed, there is some evidence to suggest that the dimensions of employment brand equity will affect job seekers intentions. For example, Turban and Greening (1997) found that familiar firms were viewed more favorable as employers than were unfamiliar firms. Futher, several recruitment studies suggested that perceived attitudes and attributes toward a job opportunity will influence job seeker's early reactions to potential employers (e.g. Tom, 1971; Belt \& Paolillo, 1982; Gatewood et al. 1993; Turban \& Greening, 1997; Highhouse, et al., 1999). Thus, we expect that job seekers' intentions to pursue job opportunities with an organization will be positively affected by brand awareness, associations, and perceived quality.

Hypothesis 5: Brand awareness, brand associations, and perceived quality will all be positively related to job seekers intentions to pursue job opportunities.

\section{METHOD}

We collected data that matched responses from staffing managers at 87 companies (measure of recruitment practices) and responses from 254 graduating students (measures of employment brand equity and intentions). The companies that participated in the study are from many different industries and differed in terms of total number of employees. Student sample was collected from four major colleges in a northeastern university in US. We randomly assigned five companies from the 87 responded companies to each student survey form. Each student supplied their answers to survey questions to the five randomly selected companies. Since each student rated multiple companies in the survey, this allows us to conduct within-subject analysis on the survey data.

\section{Measures}

Company Recruitment Practice. Literature review and pilot study on independent sample were used to identify company's early recruitment practices, many of which have not been systematically studied. We then matched these recruitment practices with the activities in the marketing mix literature and categorized these items into four sets. Principal component factor analysis was used to determine the internal consistency of responses to these sets of items generated to measure company recruitment practices. These four scales were summarized as advertising $(\alpha=.73)$, trade show $(\alpha=.78)$, sponsorship $(\alpha=.87)$, and key contact $(\alpha=.80)$. We formed composites by averaging the ratings for the items associated with each practice.

Employment Brand Equity Dimensions. The student survey collected data on four measures to assess the three dimensions of brand equity: 1) Awareness is meant to capture the extent to 
which individual respondents are aware of the organization that they are rating and was measured with a 5-item scale adapted from Stevens et al. (2001). 2) Association was assessed by two components: a) Attraction to the company, assessed by six-item measure $(\alpha=.90)$ adapted from Taylor and Bergmann (1987) but included additional items to provide a broader range of general assessments of the company. b) Perceived job attributes. Prior recruitment studies have measured job seekers' perceptions of large numbers of job attributes (e.g., Behling, Labovitz, \& Gainer, 1968; Jurgensen, 1978; Lacy, Bokermeier \& Shepard, 1983; Harris \& Fink, 1987; Powell, 1991; Turban, Eyring \& Campion, 1993). We identified 8 attributes about which potential applicants might have some basic knowledge in the early stage: salary, location, type of job, advancement opportunities, job security, working environment, benefit, work-life balance. 3) Perceived Quality is defined as the consumers' judgment about a product's overall excellence or superiority (Kirmani \& Zeithaml, 1993; Keller, 1998). Perceived quality is a subjective global assessment (Keller, 1998). Fit in the recruitment setting has been measured both objectively (e.g. O'Reilly, Chatman, \& Caldwell, 1991) and subjectively (Cable \& Judge, 1996, Judge and Cable, 1997). In this study, to match with the subject nature of perceived quality, we adapt the subject measures from Judge and Cable (1997). Sample items include "In general, the employment opportunity in this organization would fit my needs," and "The value and "personality" of this organization reflects my own value and personality" ( $1=$ strongly disagree; $5=$ strongly agree; $\alpha=.89$ ). Individual items for each scale can be obtained from the authors.

Intentions to Pursue Job Opportunities. The job seekers' intentions to apply or join the company were assessed by questions adapted from Taylor and Bergmann (1987). Two of the items we used to assess intentions to apply (e.g., "If I saw a job opening for this organization, I would apply for it."), and two items were used to assess intentions to join the organization if an offer was made (e.g., "If this organization offered me a job, I would probably accept it."). Items were assessed on a five-point scale ( $1=$ strongly disagree; $5=$ strongly agree) and showed high reliability $(\alpha=.94)$.

\section{RESULTS AND DISCUSSION}

Hypotheses 1 through 4 predicted that recruitment practices have positive effects on job seekers' perceived employment brand equity. We regressed all of the recruitment practices on the individual brand equity items at the same time to control for potential multicollinearity between the recruitment practices. It appears that participation in job fairs had the most consistent effect on perceptions of brand equity as it was significantly related to each of the four dimensions (awareness B-value $=.11, \mathrm{p}<.01$; attraction $\mathrm{B}$-value $=.16, \mathrm{p}<.01$; perceived attributes B-value $=.13, \mathrm{p}<.01$; perceived quality $\mathrm{B}$-value $=.14, \mathrm{p}<.01)$. Building relationships with key university contacts was also significantly related to each of the four brand equity dimensions (awareness B-value $=.22, \mathrm{p}<.01$; attraction $\mathrm{B}$-value $=.11, \mathrm{p}<.01$; perceived attributes B-value $=.09, \mathrm{p}<.05$; perceived quality $\mathrm{B}$-value $=.08, \mathrm{p}<.05)$. Sponsorship activities also seem to be valuable tools for affecting students' perceptions of both attraction (B-value $=.09, \mathrm{p}<.05$ ) and perceived attributes $(\mathrm{B}$-value $=.08, \mathrm{p}<.05)$. We were surprised that our measure of advertising was not significantly related to any of the dimensions of job seekers' perceived employment brand equity. Thus, our results showed mixed support for Hypotheses 2 through 5. 
Although there is some evidence that informal media may outperform formal media in the recruitment source studies, it is surprising that we did not find any significant relationship between company's advertisement activities and job seekers' perceived employment brand equity. We focused on media sources such as television and radio, but students may be more likely to focus their search for information on more traditional forms of campus job advertising (e.g., job postings, company brochures). Future research may wish to examine if other types of job seekers are influenced by the broader sources of media that we measured in our study.

Hypothesis 5 predicted that perceived employment brand equity has positive effect on the job applicants' intentions to apply for or join the company. As shown in Table 2, our results showed that two of the three dimensions of the employment brand equity were significantly related to intentions to pursue job opportunities. Further, the three brand equity dimensions explain a large portion of the overall variance in job seekers' intentions $\left(\mathrm{R}^{2}=.42\right)$. Overall, we found strong support for Hypothesis 5.

We were surprised that awareness was not significantly related to intentions to pursue job opportunities. Marketing literature suggests that awareness may have an indirect effect on intentions to purchase a product, because increased awareness will aid in the recall of additional brand information (i.e., generalized and specific perceptions of the product, perceptions of product quality). Therefore, we followed the mediation test outlined by Baron and Kenny (1986) to test for indirect effects of familiarity on job seeker intentions through attractions, perceived job attributes and perceived quality. We found that awareness indirectly affects intentions to pursue a job opportunity through its effects on the other dimensions of brand equity.

Overall, we found that a mix of recruitment activities were related to three dimensions for brand equity and that these brand equity dimensions were significantly related to students' intentions to pursue job opportunities. Organizations that hope to create larger applicant pools should consider how to use the mix of recruitment activities to leverage their employment brand equity, and eventually influence job seekers' intention to pursue employment opportunities.

Given the promising results for the relationship between employment brand equity and intention, an important subject for future research is exploring the relationship between employment brand equity and job seekers' actual decisions of application and offer acceptance. More critically, future research along the same line should examine the immediate consequences of employment brand equity on organizational recruitment outcomes, such as the size and quality of the applicant pool, applicant composition, offer-acceptance rate, and time to fill the position (Barber, 1998). Effort should also be made to link employment brand equity with longer term post-hire outcomes, such as performance or turnover.

\section{REFERENCE AVAILABLE FROM THE AUTHORS}

